\title{
Effects and Mechanism of Blue Light on Monascus in Liquid Fermentation
}

\author{
Xiaowei Zhang ${ }^{1}$, Wenqing Liu ${ }^{1}$, Xiying Chen ${ }^{1}$, Junhui Cai ${ }^{2}$, Changlu Wang ${ }^{3, *}$ and \\ Weiwei He ${ }^{2, *}$ \\ 1 College of Food Science \& Engineering, Xuchang University, Xuchang 461000, China; \\ xiaoweizhang1982@163.com (X.Z.); m13298265891@163.com (W.L.); m15993640173@163.com (X.C.) \\ 2 Key Laboratory of Micro-Nano Materials for Energy Storage and Conversion of Henan Province, \\ College of Advanced Materials and Energy, Institute of Surface Micro and Nano Materials, \\ Xuchang University, Xuchang 461000, China; cjhyinian@163.com \\ 3 Department of Food Biotechnology, Tianjin University of Science and Technology, 1038 Dagu South Road, \\ Hexi District, Tianjin 300222, China \\ * Correspondences: clw123@tust.edu.cn (C.W.); heweiweixcu@gmail.com (W.H.)
}

Academic Editors: Hui Wei and Derek J. McPhee

Received: 9 September 2016; Accepted: 23 February 2017; Published: 1 March 2017

\begin{abstract}
The effect of light on Monascus and the underlying mechanism have received a great deal of interest for the industrial application of Monascus pigments. In this study, we have examined the effects of blue light on the culture morphology, mycelium growth, pigments, and citrinin yield of Monascus in liquid-state and oscillation fermentation, and explored the mechanism at a physiological level. It was found that blue light affected the colony morphology, the composition (chitin content), and permeability of the Monascus mycelium cell wall in static liquid culture, which indicates blue light benefits pigments secreting from aerial mycelium to culture medium. In liquid oscillation fermentation, the yields of Monascus pigments in fermentation broth (darkness $1741 \mathrm{U} / \mathrm{g}$, blue light $2206 \mathrm{U} / \mathrm{g}$ ) and mycelium (darkness $2442 \mathrm{U} / \mathrm{g}$, blue light $1900 \mathrm{U} / \mathrm{g}$ ) cultured under blue light and darkness are different. The total pigments produced per gram of Monascus mycelium under blue light was also higher $(4663 \mathrm{U} / \mathrm{g}$ ) than that in darkness $(4352 \mathrm{U} / \mathrm{g})$. However, the production of citrinin $(88 \mu \mathrm{g} / \mathrm{g})$ under blue light was evidently lower than that in darkness $(150 \mu \mathrm{g} / \mathrm{g})$. According to the degradation of citrinin caused by blue light and hydrogen peroxide, it can be concluded that blue light could degrade citrinin and inhibit the catalase activity of Monascus mycelium, subsequently suppressing the decomposition of hydrogen peroxide, which is the active species that degrades citrinin.
\end{abstract}

Keywords: Monascus; catalase; blue light; citrinin yield; photodegradation

\section{Introduction}

As a natural food colorant, Monascus pigments have been applied for thousands of years in China and have potential for wide industrial applications [1,2]. Multiple studies have reported that Monascus not only produces pigments that can improve sensory characteristics of food, but also generates many secondary metabolites with physiological activities such as anti-hyperlipidemia [3], antioxidant [4], anti-inflammatory [5], antihypertension [6], antibiosis [7], memory improvement [8,9], and so on. Monascus is widely utilized as a food additive in 20 kinds of food without any adverse health effects $[1,10]$. However, scientists have reported that citrinin, which is toxic to human kidney and liver, is widespread in Monascus [11,12]. Therefore, approaches for reducing the level of citrinin in Monascus products have become an important task for Monascus researchers. Yang et al. [13] found that with a three-stage aeration process with shifting oxygen supply in a $10 \mathrm{~L}$ fermentor, pigment production was 
increased by $29.6 \%$ and citrinin concentration was reduced by $79.5 \%$ compared to constant one-stage cultivation. Hajjaj et al. [14] showed that adding different amino acids (especially histidine) used as sole nitrogen sources to liquid medium has a significant impact on the production of water-soluble red pigments and citrinin in fermentation products. Furthermore, Haggblom et al. [15] reported that blue light inhibited alternariol and alternariol monomethyl ether production by $69 \%$ and $77 \%$, respectively. Fanelli et al. [16] summarized recent findings on the effect of specific light wavelength and intensity on mycotoxin biosynthesis in the main toxigenic fungal genera. Fanelli et al. [17] also found the influence of different light wavelengths on the biosynthesis of ophiobolin A by Bipolaris maydis are different; white light allowed the highest production of the metabolite, but blue and green light showed an inhibitory effect, reducing the production to 50\%. As an important environmental factor, light, specifically the shorter-wavelength blue light, plays a key role in physical processes of many fungi [18], including entrainment and resetting of circadian clock, biosynthesis of photoprotective pigments, induction of asexual conidiospores, and so on. As an important strain in industrial production [19], it is known that the colony morphology, spore germination, sporulation, pigment yield, and distribution of Monascus are sensitive to light. Bühler et al. [20] found light intensity is an important factor that can inhibit the growth and pigment production of Monascus ruber, and growth and pigment production were higher in Petri dishes and flasks exposed to red light and in the absence of light. Chen et al. [21] proved excessive blue light (constant exposure to blue light of 100 lux) reduced the yields of six pigments in mycelium, but an appropriate illumination level of blue light (exposure to 100 lux of blue light once for $30 \mathrm{~min} /$ day and to 100 lux of blue light once and twice for $15 \mathrm{~min} /$ day) could increase production of some pigments, and affected the growth as well as the expression levels of pigment biosynthetic genes in Monascus. All studies have proved light (especially blue light) has an apparent effect on Monascus growth, production of metabolites (pigments, monacolin K, citrinin, and so on), and the expression of related genes. It is well known that the yield of metabolites is not only determined by the expression of related genes, but is also related to the composition of cell, enzyme activity, and so on. However, there are few reports concerning the effect of blue light on cell composition and stability of citrinin. In this work, we have employed liquid-state fermentation for studying the effects of continuous blue light on mycelium growth, pigments, citrinin content, and the composition of Monascus mycelium wall, and we discuss the influence and mechanism of blue light on Monascus citrinin yield. Our findings will provide insights into future studies of fungal growth and metabolite production in blue light conditions. Furthermore, our study investigated the main reason that the yield of pigments and citrinin are different when exposed to blue light and darkness, and our results will provide evidence for technical and theoretical application of optically controlled fermentation for raising yield of Monascus pigments and decreasing yield of citrinin.

\section{Results and Discussion}

\subsection{Effect of Blue Light on Monascus Colony Phenotype in Static Liquid Culture}

Half of the Monascus culture was covered (dark conditions) with tinfoil paper for comparison, and the other half was continuously cultured under blue light for 5 days at $30^{\circ} \mathrm{C}$, as described in Section 3.3. The colony phenotype of the culture exposed to blue light for 5 days is shown in Figure 1.

In static liquid culture, Monascus pellicles appeared gray and deep-red under blue light and in darkness, respectively. This suggested that Monascus pellicles treated with blue light had lower pigment content than those kept in darkness. It also implied that blue light might have a great influence on Monascus phenotype. Figure 2 shows the colony phenotype of the culture before and after removal of tinfoil paper on day 5, and additional exposure to blue light for $8 \mathrm{~h}$.

Figure 2 shows that after blue light exposure for $8 \mathrm{~h}$, the deep-red pellicle that was previous grown in darkness presented the same phenotype as those that were continuously cultured in blue light. This suggested that Monascus is sensitive to the presence of blue light, and can adapt to the blue-light environment by adjusting its pigment content in the pellicle in order to satisfy its own survival needs. 


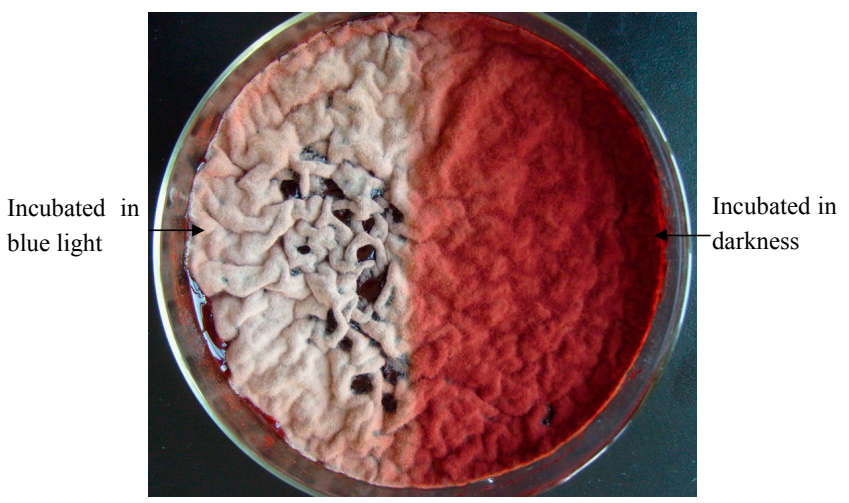

Figure 1. Effect of blue light on Monascus culture morphology in liquid fermentation. Left part and right part of the culture dish were separately exposed to either blue light or protected by tinfoil paper for 5 days.

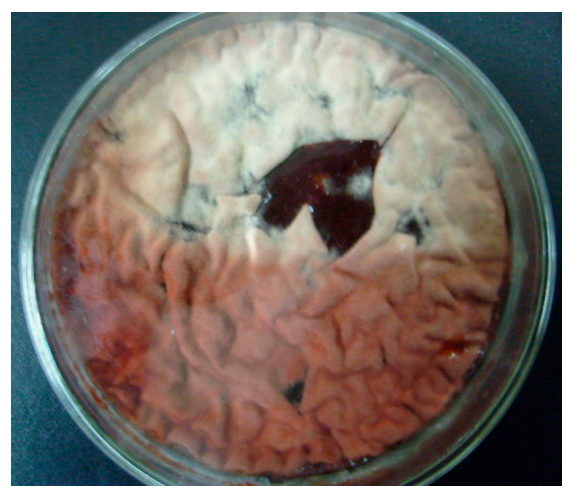

(a)

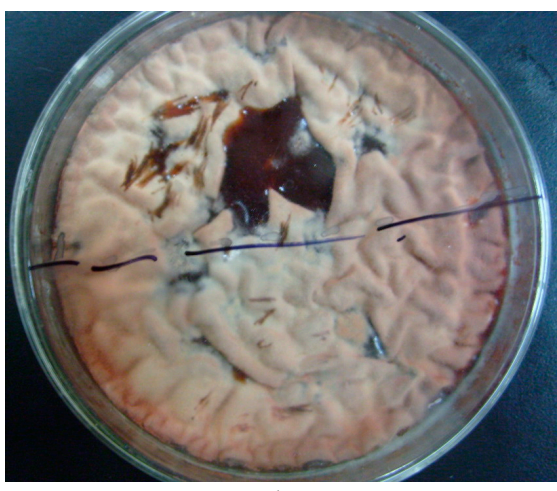

(b)

Figure 2. Changes in Monascus culture morphology after exposure to blue light. (a) Culture morphology of Monascus cultured under blue light for 5 days with tinfoil paper covering the bottom part; (b) Morphology of the culture in (a) exposed to blue light for additional $8 \mathrm{~h}$ after removing the tinfoil paper.

\subsection{Possible Explanation for the Reduction in Monascus Pellicle Pigment Content after Blue Light Exposure}

To find out the reasons for blue light affecting the culture morphology of Monascus, four of the pellicles, which appeared deep-red after 5 days of culturing in darkness, were selected. Three of these pellicles were tiled onto three pieces of clean glass; one of them received no treatment while the others were sterilized under high-pressure steam to inactivate Monascus. One inactivated Monascus pellicle was transferred onto a fresh solid flat surface, and the other remained on the clean glass. The fourth selected pellicle was transferred onto a fresh solid flat surface in order to preserve its physiological activities. We found that the four pellicles were exposed to blue light irradiation for $8 \mathrm{~h}$, the fourth pellicle, having physiological activities, showed the same pale appearance as pellicles cultured in continuous blue light. Although the pellicle that did not receive sterilization was less vibrant than pellicles cultured in darkness, it was still deep-red in color after exposure to blue light for $8 \mathrm{~h}$. On the other hand, sterilized pellicles on glass and fresh solid flat surfaces showed minor differences in pigment color before and after blue light exposure. These phenomena are displayed in Section 2.1. Our results suggested that the reduction of Monascus pigment content after blue-light irradiation could mainly be attributed to the physiological activities of Monascus [20,22], rather than the photodegradative effect of blue light on Monascus pigments. Our findings also supported that blue-light receptors are present in Monascus (WC-1 and WC-2 have been reported as blue-light receptors in fungi $[20,21])$. It is possible that the induction and signal transduction through blue-light receptors 
in Monascus could be responsible for the difference in responses of Monascus cultured in various light conditions.

\subsection{Effect of Blue Light on Monascus Mycelium Permeability}

Results described in Sections 2.1 and 2.2 indicate that blue light could affect Monascus physiological activities. Mycelium membrane permeability is an important physiological activity, so it is very necessary to discuss the effect of blue light on Monascus mycelium permeability. The effect of blue light on Monascus resting membrane permeability, performed as described in Section 3.4, is shown in Figure 3. Figure 3 shows the absorbance at $510 \mathrm{~nm}$ of sterile water in blue light was 0.82 , which was significantly higher than the absorbance of 0.62 obtained from sterile water in darkness. This showed that Monascus pigment content in sterile water was higher under blue light. The Monascus pigments in sterile water could only be derived from the pellicle since nutrient was almost entirely absent in sterile water, which prevented any Monascus growth. Our results suggested that blue light enhances release of Monascus pigments from pellicles to the surrounding environment. In addition, mycelium cell permeability of Monascus was also improved by exposure to blue light.

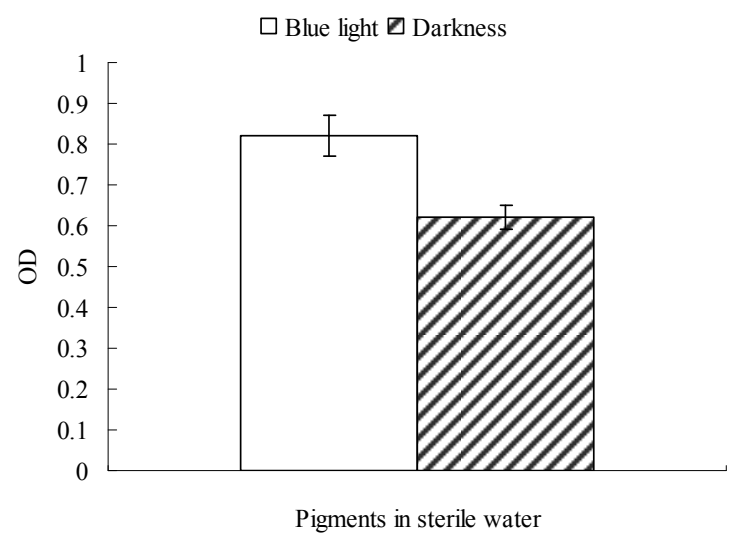

Figure 3. Effect of blue light on resting cell permeability of Monascus. Six resting pellicles (with the same pigment production) were respectively spread on six culture dishes containing $10 \mathrm{~mL}$ sterile water. Three pellicles were irradiated with blue light $\left(0.16 \mathrm{~mW} / \mathrm{cm}^{2}\right)$ for $8 \mathrm{~h}$ while the others were kept in darkness. The absorbance at $510 \mathrm{~nm}$ of the distilled water was determined after $8 \mathrm{~h}$.

\subsection{Effect of Blue Light on the Composition of Monascus Mycelium Wall}

It was established that blue light had an effect on Monascus mycelium permeability, as discussed in Section 2.3. However, mycelium permeability is related to the composition of Monascus mycelium wall. Therefore, it is necessary to discuss the effect of blue light on the composition of Monascus mycelium wall. Dry Monascus mycelia that were cultured for 4-10 days in darkness and under continuous blue light were selected, respectively. In general, fungi mycelium wall is mainly composed of chitin, whose content is determined by the measurement of glucosamine [23]. Glucosamine content in the Monascus mycelia was determined according to the method described in Section 3.9. Results are shown in Figure 4. As revealed in Figure 4, glucosamine content in Monascus mycelium from cultures under blue light was lower than those in darkness throughout the entire culture period. This indicated that blue light could affect chitin content in the Monascus mycelium cell wall, which could further influence the permeability of the Monascus mycelium cell, thereby enhancing Monascus pigment secretion from aerial hyphae to culture medium. These observations were consistent with the measurements of pigment content in sterile water after subsequent blue light irradiation. 


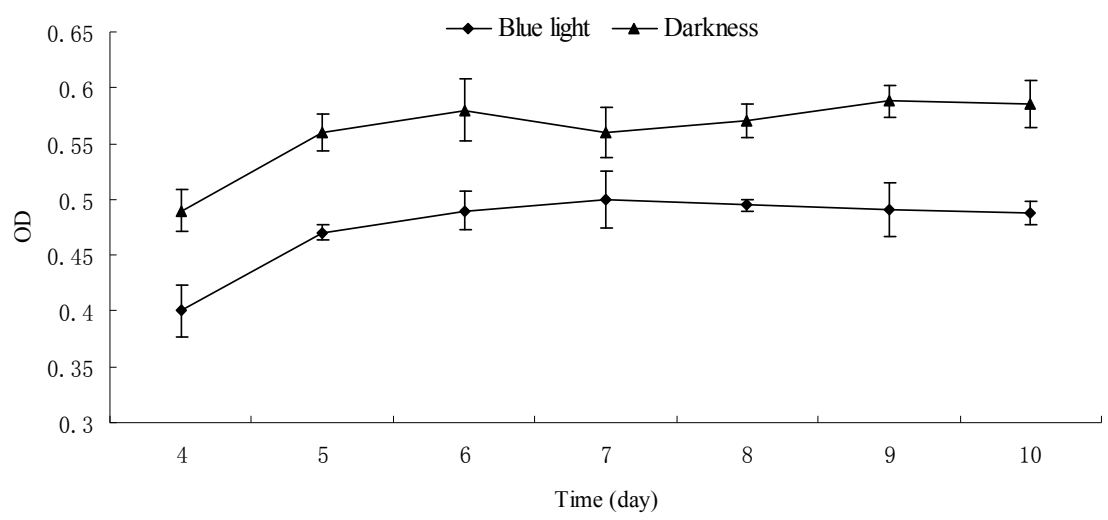

Figure 4. Effect of blue light on glucosamine content of Monascus mycelium wall. Monascus mycelium wall is composed of chitin, whose content is determined by the measurement of glucosamine released by the acid hydrolysis of chitin. The amount of glucosamine in Monascus mycelium wall cultured under blue light and darkness was determined by the absorbance at $530 \mathrm{~nm}$. Experimental conditions are described in Section 3.9.

\subsection{Effect of Blue Light on the Growth and Pigment Yield of Monascus Cultured by Liquid Oscillation}

Dry Monascus mycelium weight and pigment production in fermentation broth and mycelium of Monascus cultured under blue light and in darkness were determined. The results are shown in Figure 5.

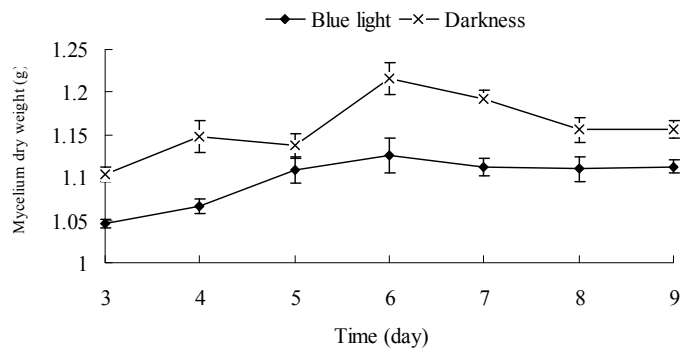

(a)

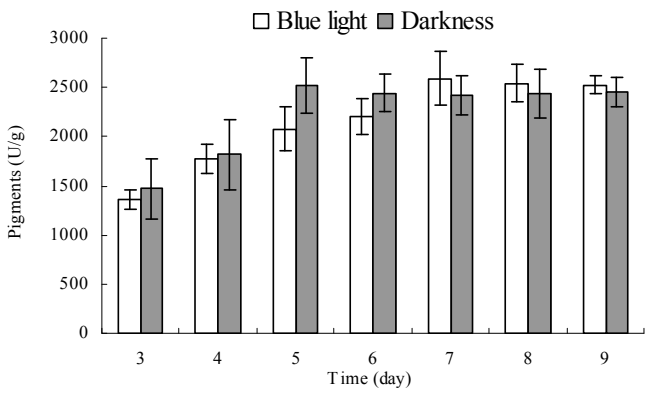

(c)

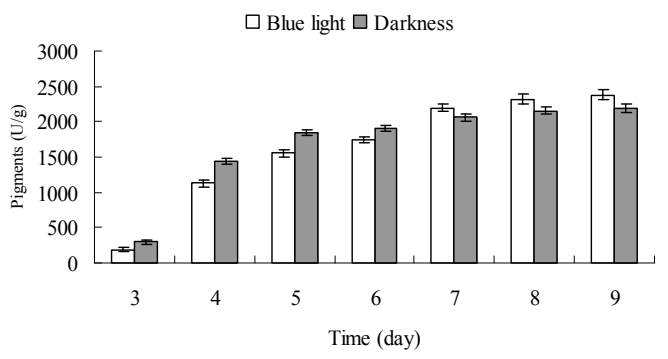

(b)

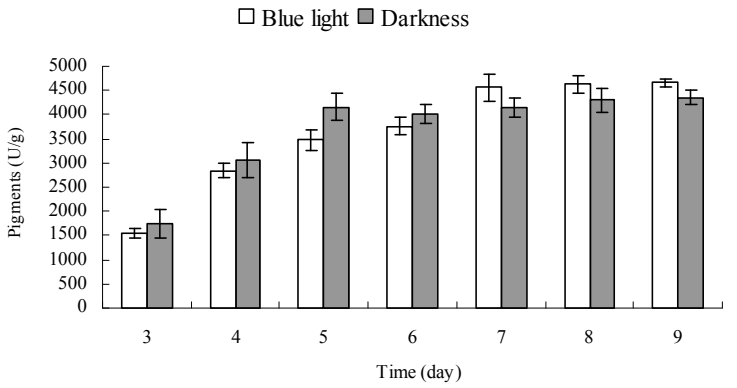

(d)

Figure 5. Effect of blue light on Monascus mycelium weight and Monascus pigment production. (a) Effect of blue light on the weight of Monascus mycelium; (b-d) Effect of blue light on Monascus pigment production in fermentation broth and Monascus mycelium, and total pigment production, respectively. Monascus was cultured by liquid oscillatory fermentation at $30{ }^{\circ} \mathrm{C}, 180 \mathrm{r} / \mathrm{min}$ for 9 days under blue light $\left(0.16 \mathrm{~mW} / \mathrm{cm}^{2}\right)$ and in darkness. The growth of mycelium and the yield of Monascus pigment production under blue light and in darkness were respectively determined by the mycelial dry weight and absorption at $510 \mathrm{~nm}$. 
The mycelium dry weight of Monascus cultured for 6 days under blue light and in darkness reached a maximum value of $1.126 \mathrm{~g}$ and $1.216 \mathrm{~g}$, respectively (Figure 5a). The mycelium dry weight of Monascus cultured under blue light was fairly stable after 6 days, however, that of Monascus cultured in darkness decreased noticeably. The mycelium dry weight of Monascus cultured under blue light was lower than that of those cultured in darkness throughout the entire culture process. This could be attributed to the fact that blue light is not conducive to the growth of Monascus, which is consistent with the results of Chen [21]. In the early stage of fermentation (3-6 day), the pigment contents in fermentation broth and mycelium under blue light were less than those in darkness (Figure 5b-d). This could be explained by blue light leading to a certain amount of degradation of Monascus pigments, as shown in Figure 6. In this early stage, synthesis of Monascus pigments is less substantial, therefore, any decomposition caused by blue light would be more obvious. When mycelium weight reached the maximum on day 6, pigments in fermentation broth under blue light increased significantly. The pigment contents of Monascus in fermentation broth grown under blue light for on days 6 and 7 were, respectively, $1741 \mathrm{U} / \mathrm{g}$ and $2194 \mathrm{U} / \mathrm{g}$. The increase in pigment content in fermentation broth in darkness was not as noticeable as that exposed to blue light. The pigment yields of Monascus in fermentation broth grown in darkness on days and 7 were, respectively, $1900 \mathrm{U} / \mathrm{g}$ and $2060 \mathrm{U} / \mathrm{g}$. After 6 days, Monascus pigment yield in mycelium cultured under blue light continued to increase; however, the pigment content in mycelium cultured in darkness remained fairly unchanged. The pigment contents in Monascus mycelium incubated under blue light and darkness for 7 days were $2593 \mathrm{U} / \mathrm{g}$ and $2417 \mathrm{U} / \mathrm{g}$, respectively. Results in Section 2.4 showed that chitin content of mycelium wall of Monascus cultured under blue light was less than that in darkness, which would influence the permeability of Monascus mycelium cell, enhancing Monascus pigment secretion from aerial hyphae to culture medium. Therefore, it is likely that pigments within the mycelium cultured under blue light were more easily transported from the inside to the outside of the mycelium than those cultured in darkness. This would also explain the noticeable increase in pigment content of fermentation broth cultured under blue light after 6 days. Due to the decrease in feedback inhibition of Monascus pigment synthesis under blue light, pigment production in mycelium continued to increase, and pigment yield per unit mycelium weight was higher than that cultured in darkness. The total pigment yields produced by a unit mycelium weight cultured under blue light and in darkness after 9 days were, respectively, $4663 \mathrm{U} / \mathrm{g}$ and $4352 \mathrm{U} / \mathrm{g}$.

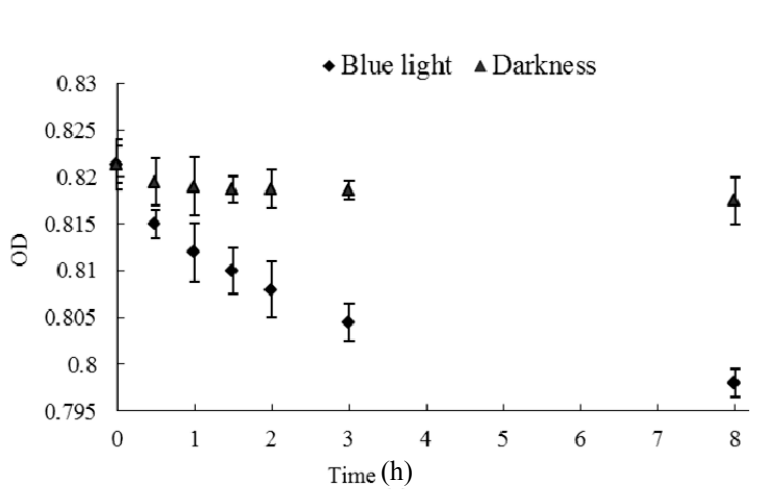

(a)

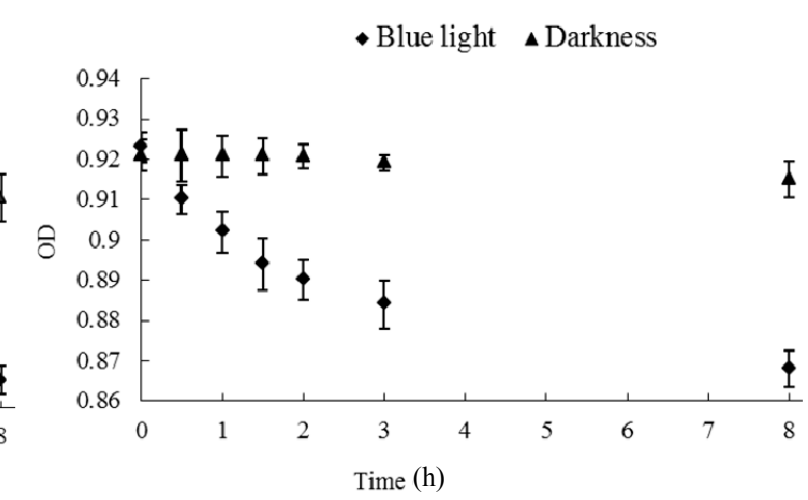

(b)

Figure 6. Effect of blue light on the stability of Monascus pigments in fermentation broth and mycelium. (a) The stability of Monascus pigments in fermentation broth; (b) the stability of Monascus pigments in hyphae. Monascus pigments in fermentation broth and mycelium ethanol extraction were randomly assigned to two groups of three samples. One group was exposed to blue light while the other group was kept in darkness. Absorbance at $510 \mathrm{~nm}$ of pigments' solution was determined every $20 \mathrm{~min}$, and the average absorbance of three samples was calculated. 


\subsection{Influence and Mechanism of Blue Light on Monascus Citrinin Yield in Liquid-State Fermentation}

To investigate the influence of blue light on Monascus citrinin yield, the citrinin yields of Monascus cultured by liquid-state fermentation under blue light and in darkness were dynamically measured. Results are shown in Figure 7. Figure 7 shows that citrinin yields of Monascus cultured by liquid-state fermentation under blue light and darkness simultaneously reached maximum levels of $90 \mu \mathrm{g} / \mathrm{g}$ and $160 \mu \mathrm{g} / \mathrm{g}$, respectively. In the course of cultivation (3-9 days), the citrinin yield under blue light was lower than in darkness. At the end of fermentation (9 days), the citrinin yields of Monascus under blue light and darkness were, respectively, $88 \mu \mathrm{g} / \mathrm{g}$ and $150 \mu \mathrm{g} / \mathrm{g}$. During the entire liquid-state fermentation process, the weight of Monascus mycelium under the blue-light culture condition was lower than that in darkness; however, the difference in mycelium weight was not the ultimate reason that led to a 50\% decrease of final citrinin yields between Monascus cultured under the two conditions. In fact, the degradation of citrinin caused by blue light in fermentation broth could be one attributing factor. In addition, Monascus contains light photoreceptors that allow for blue light inductive signaling, which, in turn, leads to changes of Monascus intracellular metabolic pathways that ultimately affect the synthesis of enzymes that degrade citrinin or inhibit the synthesis of citrinin in Monascus. In order to investigate the mechanism that contributes to the decrease in citrinin content under blue light irradiation during Monascus liquid-state fermentation, we performed the following experiments.

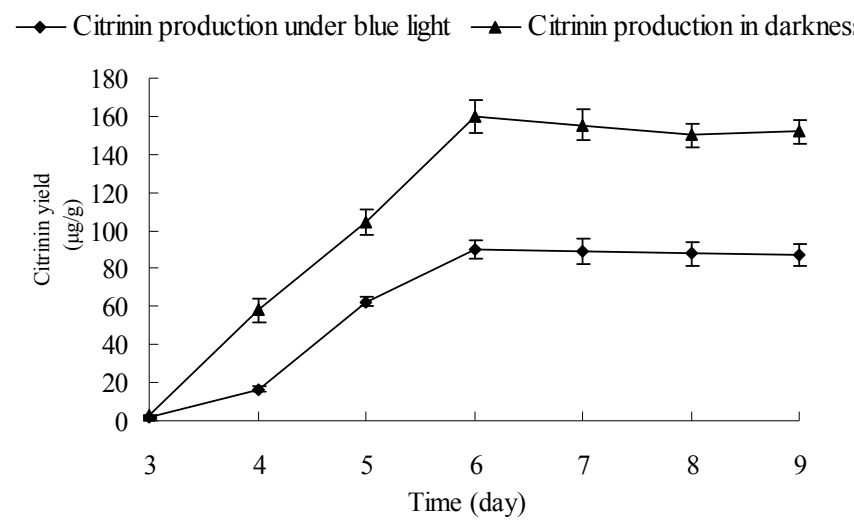

Figure 7. Effect of blue light on citrinin production. Experimental conditions are described in Section 3.8. Monascus was cultured by liquid oscillatory fermentation at $30^{\circ} \mathrm{C}, 180 \mathrm{r} / \mathrm{min}$ for 9 days under blue light $\left(0.16 \mathrm{~mW} / \mathrm{cm}^{2}\right)$ and in darkness. The citrinin production in different culture condition were determined by high-performance liquid chromatograph.

\subsection{Effect of Blue Light on Citrinin Degradation}

Changes in citrinin content in methanol solution containing citrinin standard and in ethanol extraction containing Monascus liquid fermentation broth were dynamically examined under blue light irradiation and in darkness. Figure 8 shows that blue light affects degradation of citrinin in both methanol solution with citrinin standard and in ethanol extraction with liquid fermentation of Monascus. This can mainly be attributed to the presence of conjugated bonds in the citrinin molecule, which leads to electron transition after absorbing short-wavelength photons such as blue light. The electron transition disrupts the molecular structure of citrinin and leads to degradation of citrinin [23]. The concentration of the citrinin standard in methanol solution decreased from $29.24 \mu \mathrm{g} / \mathrm{mL}$ to $3.88 \mu \mathrm{g} / \mathrm{mL}$ after 8 days of blue-light irradiation, while the citrinin concentration of Monascus in the liquid fermentation product reduced from $9.81 \mu \mathrm{g} / \mathrm{mL}$ to $5.29 \mu \mathrm{g} / \mathrm{mL}$. Based on these observations, blue light appeared to have a stronger effect on the degradation of citrinin standard. The lesser effect of blue light on degradation of Monascus fermentation broth may be due to the presence of a variety of pigments, especially red pigments, in the fermentation liquid, which absorbed blue light and resulted in a decrease in blue-light permeability. The intensity of citrinin absorption of blue 
light in fermentation broth was also greatly weakened; therefore, the effect of blue light on citrinin degradation in fermentation broth was less drastic than that on citrinin standard solution. Our results demonstrated that the effect of blue light on citrinin degradation is one of the important reasons for the decrease in citrinin content in fermentation broth under blue light. This is consistent with the results of Schmidt-Heydt [24].
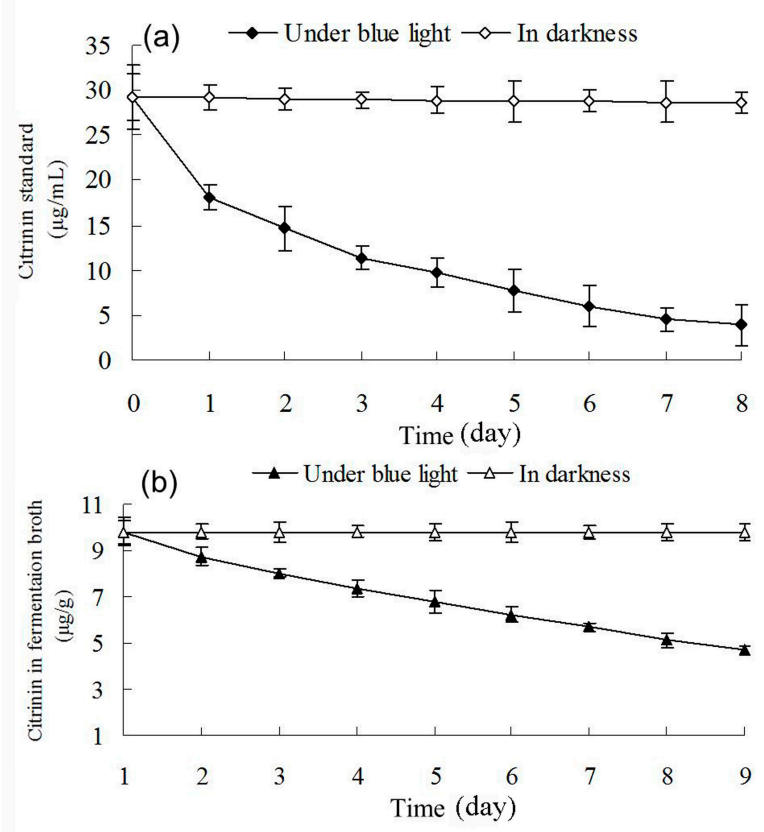

Figure 8. Effects of blue light on the stabilities of citrinin standard (a) and citrinin in fermentation broth (b). Citrinin standard methanol solution and citrinin of Monascus fermentation ethanol extraction were respectively exposed to blue light and kept in darkness. Citrinin content was determined by HPLC at specific time intervals.

\subsection{Effect of Hydrogen Peroxide on the Stability of Citrinin}

Apart from blue light, hydrogen peroxide can also degrade citrinin. Changes in citrinin content were dynamically measured after the addition of $0.05 \%$ hydrogen peroxide to methanol solution with citrinin standard and to liquid fermentation broth. Results are shown in Figure 9. Figure 9 shows that the concentration of citrinin standard reduced from $33.49 \mu \mathrm{g} / \mathrm{mL}$ to $0.31 \mu \mathrm{g} / \mathrm{mL} 30 \mathrm{~min}$ after addition of $0.05 \% \mathrm{H}_{2} \mathrm{O}_{2}$. Citrinin content in Monascus fermentation broth also decreased from 50.83 to $2.15 \mu \mathrm{g} / \mathrm{mL}$ after addition of $0.05 \% \mathrm{H}_{2} \mathrm{O}_{2}$. Our results demonstrated that $\mathrm{H}_{2} \mathrm{O}_{2}$ has a strong effect on citrinin degradation in both the fermentation liquid and in standard methanol solution, which has been reported by Hajjaj [25]. $\mathrm{H}_{2} \mathrm{O}_{2}$ is a harmful product present in aerobic eukaryotes. It is possible that $\mathrm{H}_{2} \mathrm{O}_{2}$ content in Monascus mycelium under blue light was higher than that in darkness, which could potentially explain the lower citrinin content in fermentation liquid under blue light than that in darkness. $\mathrm{H}_{2} \mathrm{O}_{2}$ content in organisms is often associated with the presence of peroxidase and catalase activity. We examined catalase activity in Monascus mycelium under blue light and in darkness in order to better understand the effect of $\mathrm{H}_{2} \mathrm{O}_{2}$ content on citrinin stability. 


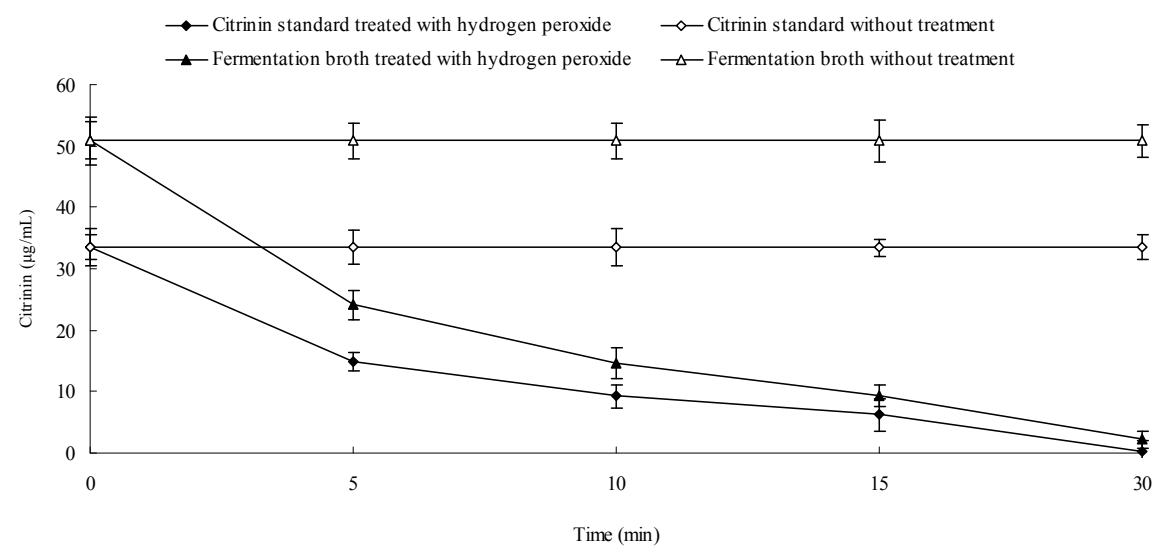

Figure 9. Effect of $\mathrm{H}_{2} \mathrm{O}_{2}$ on citrinin stability. Hydrogen peroxide solution $(0.05 \mathrm{~mL}, 30 \%)$ was respectively added to $3.6 \mathrm{~mL}$ citrinin standard methanol solution and citrinin extraction solution of Monascus fermentation broth. Citrinin content was determined by HPLC at regular time intervals.

\subsection{Effect of Blue Light on Catalase Activity in Monascus Mycelium in Liquid Fermentation}

Catalase activity in Monascus mycelium was dynamically examined from day 3 to day 9 according to the method described in Section 3.13. Results are shown in Figure 10. Figure 10 shows that the catalase activities in Monascus mycelium were $460.45 \mathrm{U} / \mathrm{g}$ and $501 \mathrm{U} / \mathrm{g}$, respectively, in early fermentation (day 3) under blue light and in darkness. The corresponding citrinin yields were $1.5 \mu \mathrm{g} / \mathrm{g}$ and $2.73 \mu \mathrm{g} / \mathrm{g}$, respectively. The catalase activities were $361 \mathrm{U} / \mathrm{g}$ and $434 \mathrm{U} / \mathrm{g}$ and the corresponding citrinin yields were $88 \mu \mathrm{g} / \mathrm{g}$ and $152 \mu \mathrm{g} / \mathrm{g}$ at the end of fermentation (day 9). The catalase activity in Monascus mycelium and the citrinin yield under blue light were both lower than those in darkness throughout the entire fermentation process. Figure 9 showed that $\mathrm{H}_{2} \mathrm{O}_{2}$ had a strong effect on degradation of citrinin. $\mathrm{H}_{2} \mathrm{O}_{2}$ content is closely linked to the activity of catalase. Catalase catalyzes the transformation of $\mathrm{H}_{2} \mathrm{O}_{2}$ into nontoxic water and oxygen, therefore, the level of catalase activity directly predicts the amount of $\mathrm{H}_{2} \mathrm{O}_{2}$ within Monascus mycelium. Catalase activity in Monascus mycelium under blue light was lower than that in darkness, which could result in an increase of $\mathrm{H}_{2} \mathrm{O}_{2}$ accumulation, which is consistent with a previous report [26]. The presence of $\mathrm{H}_{2} \mathrm{O}_{2}$ might have a destructive effect on citrinin, which would explain the lower citrinin content under blue light than that in darkness.

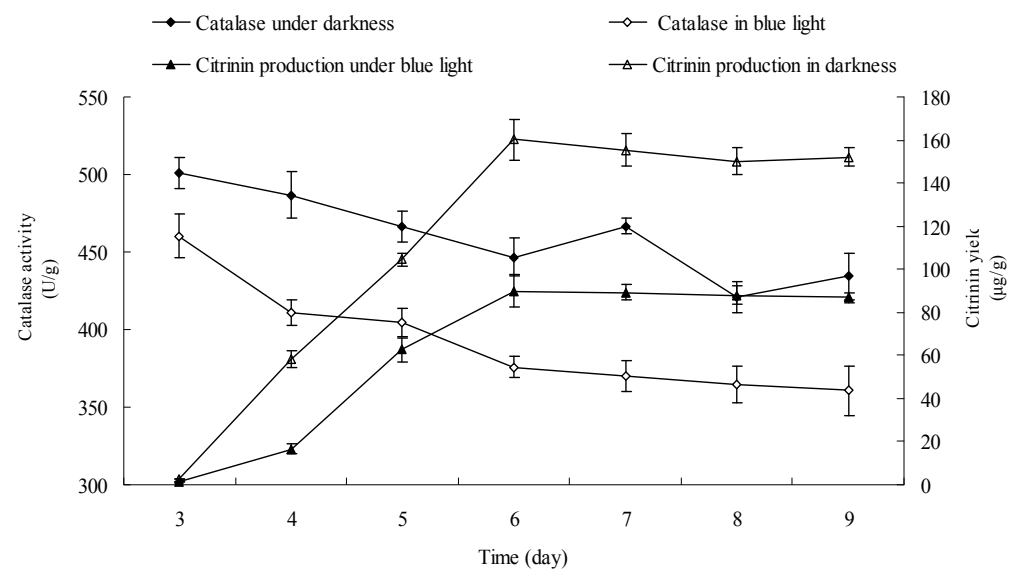

Figure 10. Effect of blue light on catalase activity of Monascus in liquid fermentation. Two grams of wet Monascus mycelium treated with blue light or kept in darkness were added to $18 \mathrm{~mL} 0.2 \mathrm{~mol} \cdot \mathrm{mL}^{-1}$, pH 7.8 phosphate buffer from fermentation of day 3. Catalase activity of $10 \%$ tissue homogenate was determined by Catalase Assay Kit (Sigma-Aldrich Corporation, St. Louis, MO, USA). 


\section{Materials and Methods}

\subsection{Strain and Culture}

Culture of Monascus ruber N, a high pigment-producing strain (offered by Professor Changlu Wang, Tianjin University of Science and Technology, Tianjin, China), was used in this study. It was maintained on malt wort extract agar slant, cultured at $30^{\circ} \mathrm{C}$ for $7-9$ days, then preserved at $4{ }^{\circ} \mathrm{C}$ and subcultured once every 3 weeks.

\subsection{Inoculum Preparation}

Five milliliters of sterile distilled water was added to a fresh fully sporulated agar slope culture. Then, the spores were scraped under strict aseptic conditions. The spore suspension was inoculated in $50 \mathrm{~mL}$ seed medium ( $\%$ rice flour, $0.25 \% \mathrm{KH}_{2} \mathrm{PO}_{4}, 0.2 \% \mathrm{NaNO}_{3}, 0.1 \% \mathrm{MgSO}_{4} \cdot 7 \mathrm{H}_{2} \mathrm{O}$. The initial $\mathrm{pH}$ of the medium was adjusted to 4.5 with lactic acid) in a $250 \mathrm{~mL}$ flask. Then, the flask was incubated at $30^{\circ} \mathrm{C}$ at $180 \mathrm{r} / \mathrm{min}$ for $30 \mathrm{~h}$. The culture was then filtered through sterile glass wool, and the spore suspension containing unclumped spores with no hyphae was adjusted to $2 \times 10^{7}$ spores per $\mathrm{mL}$. The obtained spore suspension was used as inoculum.

\subsection{Stationary Liquid Culture of Monascus}

Fifty milliliters of sterile liquid fermentation medium (rice powder $100 \mathrm{~g} / \mathrm{L}, \mathrm{KH}_{2} \mathrm{PO}_{4} 1.5 \mathrm{~g} / \mathrm{L}$, $\mathrm{NaNO}_{3} 3 \mathrm{~g} / \mathrm{L}$, and $\mathrm{MgSO}_{4} \cdot 7 \mathrm{H}_{2} \mathrm{O} 1 \mathrm{~g} / \mathrm{L}$ ) was added to a culture dish of $20 \mathrm{~cm}$ in diameter. Three milliliters of the inoculum at concentration of $2 \times 10^{7}$ spores per $\mathrm{mL}$ was also added. The culture was thoroughly mixed, and allowed to grow under blue light and darkness, respectively, for 8 days at $30{ }^{\circ} \mathrm{C}$ in a constant-temperature light growth chamber. Specifically, Petri dishes containing seed fermentation broth were randomly assigned into two groups. With all other parameters the same, one group was cultured in a constant-temperature incubator with a $1 \mathrm{~W}$ blue LED monochromatic lamp (constant biochemical incubator, LRH-250CB, Shanghai Heng Yi Scientific Instrument Co., Ltd., Shanghai, China), while the other one was cultured in darkness for 8 days.

\subsection{Effect of Blue Light on Monascus Resting Pellicle Permeability}

Six parallel Monascus pellicles (with the same pigment production), cultured as described in Section 3.3, were picked out after culturing for 6 days in darkness. The Monascus resting pellicles were rinsed with sterile water to properly remove the extracellular Monascus pigments. Then, the six resting pellicles were respectively spread on six culture dishes containing $10 \mathrm{~mL}$ sterile water. The Petri dishes were randomly assigned to two groups of three samples. One group was irradiated with blue light $\left(0.16 \mathrm{~mW} / \mathrm{cm}^{2}\right)$ for more than $8 \mathrm{~h}$ while the other group was kept in darkness. Finally, the Monascus pigment content in the sterile water culture was determined after $8 \mathrm{~h}$.

\subsection{Oscillatory Liquid Fermentation of Monascus}

Three milliliters of seed suspension at $2 \times 10^{7}$ spores $/ \mathrm{mL}$ were added to the $250 \mathrm{~mL}$ triangular flask containing $50 \mathrm{~mL}$ of fermentation liquid. The inoculated fermentation medium was cultured in a constant-temperature light growth chamber at $30^{\circ} \mathrm{C}$ at $180 \mathrm{r} / \mathrm{min}$ for 9 days under blue light $\left(0.16 \mathrm{~mW} / \mathrm{cm}^{2}\right)$ and in darkness. The specific experimental condition was the same as described in Section 3.3.

Three days after fermentation, three samples from each group were randomly examined every 24 h. Dynamic monitoring was performed to determine the dry weight of mycelium, yield of Monascus pigments, and citrinin production under different conditions in order to determine the effects and mechanism of blue light on Monascus growth, as well as pigment and citrinin contents in Monascus fermentation broth and Monascus mycelium. 


\subsection{Dynamic Monitoring of Dry Weight of Mycelium during Liquid Fermentation}

The fermentation liquid sample was placed in a centrifuge cup and centrifuged at $5000 \mathrm{r} / \mathrm{min}$. Pigment content in upper supernatant broth was determined according to methods described in Section 3.7. Mycelium in the precipitation was rinsed with distilled water and then centrifuged. The supernatant was then discarded and the whole process was repeated three times. The mycelium was dried in a vacuum oven at $60{ }^{\circ} \mathrm{C}$ and then weighed to determine the mycelial dry weight of Monascus.

\subsection{Determination of Monascus Pigment Yield in Liquid Fermentation}

\subsubsection{Determination of Pigment Yield in Fermentation Broth}

Pigments produced by the Monascus fermentation process are a mixture of three colors (red, orange, and yellow), which have maximum absorption peaks at $510 \mathrm{~nm}, 465 \mathrm{~nm}$, and $410 \mathrm{~nm}$, respectively. Pigment contents in fermentation broth can be determined at the corresponding wavelengths by ultraviolet-visible spectrophotometer. The absorbance $\mathrm{A}_{410}, \mathrm{~A}_{465}$, and $\mathrm{A}_{510}$ were used to calculate the yield of each of the three colored pigments: $S_{410}, S_{465}$, and $S_{510}$ represent the color values of Monascus yellow pigments, orange pigments, and red pigments, respectively. Changes in production of red pigments were mainly reviewed in this experiment (1).

$$
S=\frac{A \times \mathrm{n}}{G}
$$

In this formula, $S$ is the color value of fermentation broth; $G$ is the dry weight of Monascus mycelium; $\mathrm{n}$ is the dilution ratio.

\subsubsection{Determination of Pigment Yield in Monascus Mycelium}

To determine the pigment content in Monascus mycelium, $150 \mathrm{~mL} \mathrm{80 \%} \mathrm{ethanol} \mathrm{solution} \mathrm{was}$ added to a $250 \mathrm{~mL}$ triangular flask containing $5 \mathrm{~g}$ Monascus mycelium. The mixture was then treated by ultrasonic wave for $30 \mathrm{~min}$, oscillated at $180 \mathrm{r} / \mathrm{min}$ for $24 \mathrm{~h}$, and then centrifuged at $5000 \mathrm{r} / \mathrm{min}$ for 20 min. Pigment yield was calculated according to method described in Section 3.7.1.

\subsubsection{Determination of Total Pigment Yield in Unit Mycelium Dry Weight}

Total pigment yield in unit mycelium $=$ pigment yield in fermentation broth + pigment yield in mycelium.

\subsection{Determination of Citrinin Yield}

\subsubsection{Pretreatment of Monascus Sample}

Two times volume of $80 \%$ ethanol solution was added to a certain volume of Monascus fermentation broth, mixed well, incubated in water bath for $1 \mathrm{~h}$ at $60{ }^{\circ} \mathrm{C}$, oscillated every $20 \mathrm{~min}$, and centrifuged at $5000 \mathrm{r} / \mathrm{min}$ for $20 \mathrm{~min}$. Then, the supernatant was filtered through a $0.45 \mu \mathrm{m}$ Millipore filter.

\subsubsection{Condition of HPLC}

LC-10ATVP high-performance liquid chromatography was performed as follows: column Shimadzu VP-ODS C18 $(5 \mu \mathrm{m}, 250 \mathrm{~mm} \times 4.6 \mathrm{~mm})$, temperature $30^{\circ} \mathrm{C}$, injection volume $20 \mathrm{~mL}$, flow rate $1.0 \mathrm{~mL} / \mathrm{min}$, and the mobile phase acetonitrile:methanol:water $(\mathrm{pH} 2.5)=70: 10: 20$. Fluorescence detection: $\lambda_{\mathrm{ex}}=331 \mathrm{~nm}, \lambda_{\mathrm{em}}=500 \mathrm{~nm}$. 


\subsection{Determination of Monascus Mycelium Wall Component}

Monascus mycelium mainly consists of chitin. Chitin content of Monascus mycelium wall was evaluated by glucosamine measurement. Dry mycelium cultured under blue light and in darkness for 5-9 days was weighed. One milliliter of $60 \%$ sulfuric acid solution was added to $0.15 \mathrm{~g}$ of dry mycelium, and the mixture was soaked for $24 \mathrm{~h}$ at $25^{\circ} \mathrm{C}$, diluted to $1 \mathrm{~mol} / \mathrm{L}^{-1}$ in a $50 \mathrm{~mL}$ volumetric flask, heated for 20 min under high pressure and cooled, then adjusted $\mathrm{pH}$ to 7.0 with $1 \mathrm{~mol} / \mathrm{L}^{-1} \mathrm{NaOH}$. Subsequently, $1 \mathrm{~mL}$ acetyl acetone reagent $\left(3.5 \mathrm{~mL}\right.$ acetyl acetone $+50 \mathrm{~mL} 1.2 \mathrm{~mol} / \mathrm{L}^{-1} \mathrm{Na}_{2} \mathrm{CO}_{3}$ ) was added to a $2 \mathrm{~mL}$ sample ( $2 \mathrm{~mL}$ distilled water as control), and then heated for $30 \mathrm{~min}$ in a boiling water bath. Two milliliters of absolute ethanol and $1 \mathrm{~mL} p$-dimethylaminobenzaldehyde reagent $(1.333 \mathrm{~g}$ $p$-dimethylaminobenzaldehyde dissolved in $25 \mathrm{~mL}$ absolute ethanol and concentrated hydrochloric acid in brown bottle) were added, and the sample was oscillated, followed by addition of $4 \mathrm{~mL}$ absolute ethyl alcohol and thermal insulation for $1 \mathrm{~h}$ at $60^{\circ} \mathrm{C}$, prior to determination of absorbance at $530 \mathrm{~nm}[23]$.

\subsection{Effects of Blue Light on Monascus Pigments Stability}

Sixty milliliters of Monascus pigments in ethanol solution were divided into six equal parts at an absorbance value of 0.87 at $510 \mathrm{~nm}$. The six parts were randomly assigned to two groups of three. One group was exposed to blue light while the other group was kept in darkness. Absorbance was determined every $20 \mathrm{~min}$, and the average absorbance was calculated.

\subsection{Effects of Blue Light on Citrinin Stability}

A specific volume of citrinin standard methanol solution and Monascus fermentation broth were respectively exposed to blue light and kept in darkness. Citrinin content was determined by HPLC at specific time intervals.

\subsection{Effect of Hydrogen Peroxide on Citrinin Stability}

To determine the effects of hydrogen peroxide on citrinin stability, $0.05 \mathrm{~mL}$ of $30 \%$ hydrogen peroxide solution was respectively added to $3.6 \mathrm{~mL}$ citrinin standard methanol solution and citrinin extraction solution of Monascus fermentation broth. Citrinin content was determined by HPLC, as described in Section 3.8.2, at regular time intervals.

\subsection{Determination of Catalase Activity in Monascus Mycelium during Fermentation Process}

Two grams of wet Monascus mycelium treated with blue light or kept in darkness were added to $18 \mathrm{~mL} 0.2 \mathrm{~mol} \mathrm{~mL}^{-1}$, $\mathrm{pH} 7.8$ phosphate buffer from fermentation on day 3. Catalase activity of $10 \%$ tissue homogenate was determined by Catalase Assay Kit (Catalog Number CAT100 produced by Sigma-Aldrich) after cells were broken up by ultrasonic cell disruptor. One unit of catalase will decompose 1.0 micromole of hydrogen peroxide to oxygen and water per min at $\mathrm{pH} 7.0$ at $25^{\circ} \mathrm{C}$.

\section{Conclusions}

This study examined the effects of blue light on the growth and pigment yield of Monascus in liquid fermentation. We also explored the mechanism behind these effects at the physiological level. Our results showed that Monascus pigment content and mycelium cell wall composition changed drastically under blue-light irradiation. Due to the presence of photoreceptors, such as WC-1 and WC-2, Monascus mycelium cell permeability and pigment yield were affected in Monascus cultured under blue light. Finally, the citrinin yield of Monascus under blue light was 50\% lower than that cultured in darkness, suggesting that blue light could contribute to degradation of citrinin and affect the catalase activity in Monascus mycelium. However, the effect of blue light on other components of the Monascus membrane have not been discussed, and the molecular mechanism of blue light affecting the catalase activity needs to be further studied in detail. 
Acknowledgments: This work was supported by National Natural Science Foundation of China (Grant No. 31601447 and 144200510014), Program for Science \& Technology Innovation Talents in Universities of Henan Province (14HASTIT008), Plan for Scientific Innovation Talent of Henan Province (174100510014) and the grants from Henan Educational Administration (16A550005).

Author Contributions: X.Z. and W.H. conceived and designed the experiments; X.Z., C.W. provided the strains; C.W. guided the experiments; W.L. and X.C. performed the experiments; X.Z. and W.H. analyzed the data; J.C. contributed reagents/materials/analysis tools; X.Z. wrote the paper.

Conflicts of Interest: The authors declare no conflict of interest.

\section{References}

1. Vendruscolo, F.; Meinicke Bühler, R.M.; Cesar de Carvalho, J.; de Oliveira, D.; Moritz, D.E.; Schmidell, W.; Ninow, J.L. Monascus: A Reality on the Production and Application of Microbial Pigments. Appl. Biochem. Biotechnol. 2016, 178, 211-223. [CrossRef] [PubMed]

2. Singgih, M.; Julianti, E. Food Colorant from Microorganisms[M]//Beneficial Microorganisms in Food and Nutraceuticals; Springer International Publishing: Cham, Switzerland, 2015; pp. 265-284.

3. Sung, J.; Shin, J.Y.; Kim, H.; Baek, G.-H.; Yu, K.-W.; Yeon, J.; Lee, J. Anti-obesity and Anti-hyperlipidemic Activities of Fermented Coffee with Monascus ruber Mycelium by Solid-State Culture of Green Coffee Beans. J. Korean Soc. Food Sci. Nutr. 2014, 43, 341-348. [CrossRef]

4. Kwon, C.S. Effect of Red Yeast (Monascus purpureus) Rice Supplemented Diet on Lipid Profiles and Antioxidant Activity in Hypercholesterolemic Rats. J. Korean Soc. Food Sci. Nutr. 2014, 43, 16-23. [CrossRef]

5. Hsu, L.C.; Liang, Y.H.; Hsu, Y.W.; Kuo, Y.H.; Pan, T.M. Anti-inflammatory properties of yellow and orange pigments from Monascus purpureus NTU 568. J. Agric. Food Chem. 2013, 61, 2796-2802. [CrossRef] [PubMed]

6. Rochín-Medina, J.J.; Gutiérrez-Dorado, R.; Sánchez-Magaña, L.M.; Reyes Moreno, C. Enhancement of nutritional properties, and antioxidant and antihypertensive potential of black common bean seeds by optimizing the solid state bioconversion process. Int. J. Food Sci. Nutr. 2015, 66, 498-504. [CrossRef] [PubMed]

7. Zhao, G.P.; Li, Y.Q.; Yan, J.; Cui, K.Y. Antibacterial Characteristics of Orange Pigment Extracted from Monascus Pigments against Escherichia coli. Czech J. Food Sci. 2016, 34, 197-203.

8. Lee, C.L.; Lin, P.Y.; Hsu, Y.W.; Pan, T.M. Monascus-fermented monascin and ankaflavin improve the memory and learning ability in amyloid $\beta$-protein intracerebroventricular-infused rat via the suppression of Alzheimer's disease risk factors. J. Funct. Foods 2015, 18, 387-399. [CrossRef]

9. Chen, C.L.; Chang, K.Y.; Pan, T.M. Monascus purpureus NTU 568 fermented product improves memory and learning ability in rats with aluminium-induced Alzheimer's disease. J. Funct. Foods 2016, 21, 167-177. [CrossRef]

10. Muro Urista, C.; Gracida Rodríguez, J.; Abreu Corona, A.; Ainhoa Arana, C.; Alejandro Téllez, G. Pigments from fungi, an opportunity of production for diverse applications. Biologia 2016, 71, 1067-1079. [CrossRef]

11. Blanc, P.J.; Loret, M.O.; Goma, G. Production of citrinin by various species of Monascus. Biotechnol. Lett. 1995, 17, 291-294. [CrossRef]

12. Ali, N.; Blaszkewicz, M.; Mohanto, N.C.; Rahman, M.; Alim, A.; Hossain, K.; Degen, G.H. First results on citrinin biomarkers in urines from rural and urban cohorts in Bangladesh. Mycotoxin Res. 2015, 31, 9-16. [CrossRef] [PubMed]

13. Yang, J.; Chen, Q.; Wang, W.; Hu, J.; Hu, C. Effect of oxygen supply on Monascus pigments and citrinin production in submerged fermentation. J. Biosci. Bioeng. 2015, 119, 564-569. [CrossRef] [PubMed]

14. Hajjaj, H.; François, J.M.; Goma, G.; Blanc, P.I. Effect of amino acids on red pigments and citrinin production in Monascus ruber. J. Food Sci. 2012, 77, M156-M159. [CrossRef] [PubMed]

15. Haggblom, P.; Unestam, T. Blue light inhibits mycotoxin production and increases total lipids and pigmentation in Alternaria alternate. Appl. Microbiol. Biotechnol. 1979, 38, 1074-1077.

16. Fanelli, F.; Geisen, R.; Schmidt-Heydt, M.; Mule, G. Light regulation of mycotoxin biosynthesis: New perspectives for food safety. World Mycotoxin J. 2016, 9, 129-146. [CrossRef]

17. Fanelli, F.; Reveglia, P.; Masi, M. Influence of light on the biosynthesis of ophiobolin A by Bipolaris maydis. Nat. Prod. Res. 2016, 1-9. [CrossRef] [PubMed]

18. Röhrig, J.; Kastner, C.; Fischer, R. Light inhibits spore germination through phytochrome in Aspergillus nidulans. Curr. Genet. 2013, 59, 55-62. [CrossRef] [PubMed] 
19. Patakova, P. Monascus secondary metabolites: production and biological activity. J. Ind. Microbiol. Biotechnol. 2013, 40, 169-181. [CrossRef] [PubMed]

20. Bühler, R.M.M.; Müller, B.L.; Moritz, D.E.; Vendruscolo, F.; de Oliveira, D.; Ninow, J.L. Influence of light intensity on growth and pigment production by Monascus ruber in submerged fermentation. Appl. Biochem. Biotechnol. 2015, 176, 1277-1289. [CrossRef] [PubMed]

21. Chen, D.; Xue, C.; Chen, M.; Wu, S.; Li, Z.; Wang, C. Effects of blue light on pigment biosynthesis of Monascus. J. Microbiol. 2016, 54, 305-310. [CrossRef] [PubMed]

22. Miyake, T.; Mori, A.; Kii, T.; Okuno, T.; Usui, Y.; Sato, F.; Sammoto, H.; Watanabe, A.; Kariyama, M. Light effects on cell development and secondary metabolism in Monascus. J. Ind. Microbiol. Biotechnol. 2005, 32, 103-108. [CrossRef] [PubMed]

23. Babitha, S.; Soccol, C.R.; Pandey, A. Effect of stress on growth, pigment production and morphology of Monascus sp. in solid cultures. J. Basic Microbiol. 2007, 47, 118-126. [CrossRef] [PubMed]

24. Schmidt-Heydt, M.; Cramer, B.; Graf, I.; Lerch, S.; Humpf, H.U.; Geisen, R. Wavelength-dependent degradation of ochratoxin and citrinin by light in vitro and in vivo and its implications on Penicillium. Toxins 2012, 4, 1535-1551. [CrossRef] [PubMed]

25. Hajjaj, H.; Klaebe, A.; Goma, G.; Blanc, P.J.; Barbier, E. Medium-chain fatty acids affect citrinin production in the filamentous fungus Monascus ruber. Appl. Environ. Microbiol. 2000, 66, 1120-1125. [CrossRef] [PubMed]

26. Zigman, S.; Reddan, J.; Schultz, J.B.; McDaniel, T. Structural and Functional Changes in Catalase Induced by Near-UV Radiation. Photochem. Photobiol. 1996, 63, 818-824. [CrossRef] [PubMed]

Sample Availability: Not Available.

(C) 2017 by the authors. Licensee MDPI, Basel, Switzerland. This article is an open access article distributed under the terms and conditions of the Creative Commons Attribution (CC BY) license (http:/ / creativecommons.org/licenses/by/4.0/). 